\title{
Effect of early vitamin A supplementation on bronchopulmonary dysplasia in premature infants
}

\author{
Li Huang, Diqing Zhu, Gaofeng Pang \\ Department of Pediatrics, The Third Affiliated Hospital of Soochow University, Changzhou, China \\ Correspondence to: Gaofeng Pang. Department of Pediatrics, The Third Affiliated Hospital of Soochow University, Changzhou 213003, China. \\ Email: czyypp008@126.com. \\ Response to: Wu J, Wang P, Bao W, et al. Does early supplementation of vitamin A show good efficacy on the prevention of bronchopulmonary \\ dysplasia? Transl Pediatr 2022. doi: 10.21037/tp-21-575
}

Submitted Jan 19, 2022. Accepted for publication Feb 23, 2022.

doi: $10.21037 /$ tp-22-26

View this article at: https://dx.doi.org/10.21037/tp-22-26

We thank Wu et al. for his comments on the systematic review and meta-analysis: "The effects of early vitamin A supplementation on the prevention and treatment of bronchopulmonary dysplasia in premature infants: a systematic review and meta-analysis" published in Fournal of Translational Pediatrics (1). The results showed that the incidence of bronchopulmonary dysplasia (BPD) in the experimental group [-0.71, 95\% confidential interval (CI): -0.34 to -0.00 ; $\mathrm{Z}=1.98 ; \mathrm{P}=0.05]$ was lower than that in the control group. The 28-day oxygen uptake rate, 36-week survival rate, incidence of patent ductus arteriosus, days of mechanical ventilation, and 28-day ventilator in the observation group were lower than those in the control group, but there was no statistical difference between the two $(\mathrm{P}>0.05)$. The results showed that early vitamin A supplementation had no significant effect on oxygen uptake rate, 36-week survival rate, days of mechanical ventilation, and 28-day ventilator use. In the analysis of the effect of early vitamin A supplementation in the prevention and treatment of $\mathrm{BPD}$, it was found that its odds ratio (OR) value was -0.71 , which was significantly less than 1 , indicating that early vitamin A supplementation had a certain preventive effect on BPD (2). However, due to the limited number of articles included in this study, the effect of vitamin A on BPD was not significant. In the future work, we will further verify and confirm the role of vitamin $\mathrm{A}$ in the prevention and treatment of BPD through a large number of research results.

The result was based on the calculation results of RevMan5.3 software, and the OR value obtained was not within the $95 \%$ CI, which was unbelievable. Due to personal negligence, it has not been carefully checked and confirmed. According to your suggestion, the results of relevant indicators in figure 4 have been recalculated many times, and the results show that BPD incidence $[0.71,95 \%$ confidential interval (CI): 0.56 to $0.91 ; \mathrm{Z}=2.73 ; \mathrm{P}=0.006$ ].

The choice of different models can be determined based on the quality of the underlying data, with random effects models chosen if study-level variability is expected to be meaningful (3). The random effects model can be used for significant testing, rejecting the null value of the homogeneous effect size (4). If the random effects model analysis has no significant heterogeneity (that is, not significant), the fixed effects estimates will be derived. These estimates change only in the presence of significant heterogeneity (5). Therefore, the random effects model was adopted for analysis.

\section{Acknowledgments}

Funding: None.

\section{Footnote}

Provenance and Peer Review: This article was commissioned by the editorial office, Translational Pediatrics. The article did not undergo external peer review.

Conflicts of Interest: All authors have completed the ICMJE uniform disclosure form (available at https://tp.amegroups. 
com/article/view/10.21037/tp-22-26/coif). The authors have no conflicts of interest to declare.

Ethical Statement: The authors are accountable for all aspects of the work in ensuring that questions related to the accuracy or integrity of any part of the work are appropriately investigated and resolved.

Open Access Statement: This is an Open Access article distributed in accordance with the Creative Commons Attribution-NonCommercial-NoDerivs 4.0 International License (CC BY-NC-ND 4.0), which permits the noncommercial replication and distribution of the article with the strict proviso that no changes or edits are made and the original work is properly cited (including links to both the formal publication through the relevant DOI and the license). See: https://creativecommons.org/licenses/by-nc-nd/4.0/.

Cite this article as: Huang L, Zhu D, Pang G. Effect of early vitamin A supplementation on bronchopulmonary dysplasia in premature infants. Transl Pediatr 2022;11(3):425-426. doi: $10.21037 /$ tp-22-26

\section{References}

1. Huang L, Zhu D, Pang G. The effects of early vitamin A supplementation on the prevention and treatment of bronchopulmonary dysplasia in premature infants: a systematic review and meta-analysis. Transl Pediatr 2021;10:3218-29.

2. Andrade C. Understanding relative risk, odds ratio, and related terms: as simple as it can get. J Clin Psychiatry 2015;76:e857-61.

3. Spineli LM, Pandis N. Meta-analysis: Random-effects model. Am J Orthod Dentofacial Orthop 2020;157:280-2.

4. Yamaguchi Y, Maruo K, Partlett C, et al. A random effects meta-analysis model with Box-Cox transformation. BMC Med Res Methodol 2017;17:109.

5. Jackson D, Turner R. Power analysis for random-effects meta-analysis. Res Synth Methods 2017;8:290-302. 